\title{
Hypoxia-mediated immune evasion of pancreatic carcinoma cells
}

\author{
YEBIN LU, JUANJUAN HU, WEIJIA SUN, XIAOHUI DUAN and XIONG CHEN \\ Department of General Surgery, Xiangya Hospital, Central South University, Changsha, Hunan 410008, P.R. China
}

Received January 6, 2014; Accepted October 24, 2014

DOI: $10.3892 / \mathrm{mmr} .2015 .3144$

\begin{abstract}
Hypoxia is one of the characteristics of human and animal tumors. To investigate the association between hypoxia and the immune evasion of cancer cells, the present study examined paraffin sections of pancreatic tissues from patients with pancreatic carcinoma, chronic pancreatitis and normal pancreatic tissue and established a series of PANC-1 cell lines, which were cultured under various hypoxic and normoxic conditions. The results demonstrated that the expression of hypoxia-inducible $1 \alpha(\mathrm{HIF}-1 \alpha)$ in pancreatic carcinoma was significantly higher compared with that in the chronic pancreatitis and normal pancreatic tissues, which revealed that a hypoxic microenvironment existed in pancreatic carcinoma. HIF-1 $\alpha$ was inversely correlated with major histocompatibility complex class I chain-related (MIC) genes, which indicated that hypoxia was involved in tumor immune evasion. The cell experiments demonstrated that the mechanism involved shedding of the MIC from the membrane of the pancreatic carcinoma cells, which then formed soluble (s)MIC. The sMIC genes downregulated natural killer (NK) group 2, member D and the cytotoxic activity of NK cells. Depending on its activity, the nitric oxide-cyclic guanosine monophosphate-protein kinase $\mathrm{G}$ signaling pathway can either increase or inhibit immune evasion of pancreatic cancer cells.
\end{abstract}

\section{Introduction}

Through mutation, tumor cells may express novel antigens, which are recognized by the immune system. The innate and acquired immune systems are subsequently activated, resulting in tumor cell death. However, there are exceptions, in which tumor cells modify the surface antigens and alter the microenvironment to evade the immune response (1).

There is substantial evidence that hypoxia is present in malignant solid tumors and is associated with increased tumor growth, invasion, metastatic potential and resistance

Correspondence to: Professor Weijia Sun, Department of General Surgery, Xiangya Hospital, Central South University, 87 Xiangya Street, Changsha, Hunan 410008, P.R. China

E-mail: sunweijia1@hotmail.com

Key words: hypoxia, pancreatic carcinoma, natural killer cell, immune evasion to therapy (2). Fink et al (3) indicated that liver cancer cells exposed to hypoxia were more tolerant to natural killer (NK) cells compared with those cultivated under normoxic conditions.

Hypoxia-inducible factor-1 (HIF-1) is a sequence-specific DNA-binding transcription factor, which is regulated by hypoxia and transcriptionally activates the expression of several genes (4). HIF-1 consists of HIF-1 $\alpha$ and HIF-1 $\beta$ (5). HIF-1 $\beta$ is stable intracellularly, while HIF- $1 \alpha$ is associated with cellular $\mathrm{O}_{2}$ (6). The major histocompatibility complex class I chain-related (MIC) gene has seven family members; however, only the MICA and MICB genes encode proteins (7). The MICA/B proteins are located in the cell membrane and act as ligands of the NK group 2, member D (NKG2D). These proteins are rarely expressed by normal cells; however, they are expressed in a variety of malignant diseases (8-10). NKG2D is well-established as a receptor expressed on NK cells. Following ligand binding, it transfers the signal downstream to activate the cytotoxic activity of NK and T-cells (11-13).

Hypoxia in pancreatic cancer widely exists; therefore, a series of experiments was designed in order to determine whether pancreatic cancer cells resisted the cytotoxic effect of NK cells and whether the resistance was associated with hypoxia. The present study also aimed to elucidate whether the resistance observed was associated with the expression of NKG2D on NK cells and the molecule MIC on the pancreatic cancer cell membrane.

\section{Materials and methods}

Materials. Mouse anti-human MICA/B (1:150) and NKG2D (1:100) monoclonal antibodies were obtained from Santa Cruz Biotechnology, Inc, (Dallas, TX, USA). Rabbit anti-human HIF-1 $\alpha$ polyclonal antibody was obtained from Boshide Bio, Inc. (Wuhan, China). Glyceryl trinitrate (GTN) was obtained from Sabex (Boucherville, QC, Canada), KT5823 and NG-mono-methyl-L-arginine (L-NMMA) were obtained from Biyuntian (Shanghai, China) and MTT and 8-bromoguanosine cyclic monophosphate (8-Br-cGMP) were obtained from Sigma-Aldrich (St. Louis, MO, USA).

Patients and samples. Pathological specimens were obtained from 42 patients undergoing surgical resection for pancreatic carcinoma and nine patients undergoing surgical resection for chronic pancreatitis at Xiangya Hospital (Changsha, China) between April 2010 and April 2012. In addition, eight normal pancreatic tissue samples were obtained from the Xiangya 
Table I. Expression of HIF-1 $\alpha$ and MICA/B in pancreatic carcinoma, chronic pancreatitis and normal pancreatic tissues.

\begin{tabular}{|c|c|c|c|c|c|c|c|c|c|c|}
\hline \multirow[b]{2}{*}{ Sample } & \multirow[b]{2}{*}{$\mathrm{n}$} & \multicolumn{4}{|c|}{ HIF-1 $1 \alpha$} & \multirow[b]{2}{*}{ P-value } & \multicolumn{3}{|c|}{ MIC A/B } & \multirow[b]{2}{*}{ P-value } \\
\hline & & - & + & ++ & +++ & & 0 & 1 & 2 & \\
\hline Pancreatic carcinoma & 42 & 10 & 2 & 12 & 18 & & 4 & 13 & 25 & \\
\hline Chronic pancreatitis & 9 & 7 & 2 & 0 & 0 & $<0.001$ & 7 & 2 & 0 & $<0.001$ \\
\hline Normal pancreas & 8 & 0 & 0 & 0 & 0 & & 7 & 1 & 0 & \\
\hline
\end{tabular}

HIF-1 $\alpha$, hypoxia-inducible factor $1 \alpha$; MICA/B, major histocompatibility complex class I chain-related A/B .

Transplant Center (Changsha, China) or from autopsy. The general sample information for the 59 total samples, graded as previously described $(14,15)$, is shown in Table I. The study was approved by the ethics committee of Xiangya Hospital, Central South University, Changsha, China.

Cells. The PANC-1 cell line, purchased from the Resource Center of Shanghai Institutes of Biological Sciences (Shanghai, China), was maintained in a monolayer culture in Dulbecco's modified Eagle's medium supplemented with $20 \%$ fetal bovine serum (Gibco-BRL, Invitrogen Life Technologies, Carlsbad, CA, USA). NK cells were purchased from the Resource Center of Shanghai Institutes of Biological Sciences (Shanghai, China). NK cells were cultured in RPMI-1640 containing 10\% fetal bovine serum, penicillin $(100 \mathrm{U} / \mathrm{ml})$ and streptomycin $(100 \mu \mathrm{g} / \mathrm{ml})$. Interleukin (IL)-2 (1000 U/ml) was also added to the medium. Following $72 \mathrm{~h}$ of incubation the NK cells were able to be used as effector cells.

Culture conditions. In order to establish hypoxic conditions, the cells were placed in airtight chambers, which were flushed with a gaseous mixture of $4.5 \% \mathrm{CO}_{2}, 95 \% \mathrm{~N}_{2}$ and $0.5 \% \mathrm{O}_{2}$ with optional addition of GTN $(10 \mathrm{nM}), 8$-Br-cGMP $(10 \mathrm{nM})$ or KT5823 $(10 \mu \mathrm{M})$. Another group of cells was incubated with $20 \% \mathrm{O}_{2}$ and optional addition of L-NMMA $(5 \mu \mathrm{g} / \mathrm{ml})$.

Immunohistochemical analysis. The tumor samples were fixed with 10\% paraformaldehyde (Blue Star, Shanghai, China) and embedded in paraffin (Behai Chemical Industry Company, Changsha, China). Sections $(4 \mu \mathrm{m})$ were then cut from the samples using a Leica RM2135 microtome (Leica Biosystems, Bensheim, Germany) and were adhered to microscope slides. The sections were dewaxed and washed three times with phosphate-buffered saline (PBS; Sigma-Aldrich). For non-specific inhibition, each section was incubated in $10 \%$ normal goat serum (Boster, Wuhan, China) for $30 \mathrm{~min}$ at $37^{\circ} \mathrm{C}$ and then with primary antibodies, rabbit anti-human polyclonal HIF-1 $\alpha$ and the mouse anti-human monoclonal MIC A/B, overnight at $4^{\circ} \mathrm{C}$. The sections were washed three times with PBS and were incubated with secondary antibody linked with biotin and then with horseradish peroxidase (HRP)-marked anti-biotin (Boster) for $30 \mathrm{~min}$ at $37^{\circ} \mathrm{C}$. Subsequently, the sections were incubated in freshly prepared diaminobenzidine (Boster) and subsequently counterstained with hematoxylin (Boster). The sections were then observed under an optical microscope (CX41; Olympus Corp., Tokyo, Japan).
Reverse transcription quantitative polymerase chain reaction $(R T-q P C R)$ analysis. The total RNA was extracted using TRIzol reagent. RT was performed using $1 \mu \mathrm{g}$ total RNA and oligo(dT) primers (Sangon Biotech Co., Ltd, Shanghai, China) which were as follows: homo-MICA forward, 5'-AGGTACATCTGGATGGTCAG-3' and reverse, 5'-TTGTCTTCATGGATCTCACA-3' with an amplified fragment of $232 \mathrm{bp}$; homo-MICB forward, 5'-CTTCGTTACAACCT CATGGT-3' and reverse, 5'-ATATGAGTCAG GGTCCTCCT-3' with an amplified fragment of 227 bp and homo-GAPDH forward, 5'-ACCACAGTCCATGCCATCAC-3' and reverse, 5'-TCCACCACCCT GTTGCTGTA-3' with an amplified fragment of $450 \mathrm{bp}$. The PCR cycling conditions were as follows: $95^{\circ} \mathrm{C}$ for $5 \mathrm{~min}$, followed by 40 cycles of $94^{\circ} \mathrm{C}$ for $30 \mathrm{sec}$, annealing at $54^{\circ} \mathrm{C}$ for $30 \mathrm{sec}$ and $72^{\circ} \mathrm{C}$ for $30 \mathrm{sec}$, with a final extension at $72^{\circ} \mathrm{C}$ for $5 \mathrm{~min}$. Conditions were then maintained at $4^{\circ} \mathrm{C}$.

ELISA analysis. A total of two non-overlapping epitope antibodies were used for ELISA analysis. The polystyrene board plates (Boster) were coated with the mouse anti-human monoclonal MIC A/B immunoglobulin G ( $\mathrm{IgG}$ ) overnight at $4^{\circ} \mathrm{C}$, then inhibited with $5 \%$ fetal bovine serum for $2 \mathrm{~h}$ at $37^{\circ} \mathrm{C}$ and washed with PBS. Subsequently, the cell culture medium samples were added and incubated for $1 \mathrm{~h}$ at $37^{\circ} \mathrm{C}$. The plates were then washed with PBS and incubated with goat anti-mouse $\operatorname{IgG}$ antibody linked with HRP for $1 \mathrm{~h}$ at $37^{\circ} \mathrm{C}$. TMB chromogenic agent and TMB terminated liquid (Boster) were added and, following reaction, the absorbance was measured at $450 \mathrm{~nm}$ using a DU640 ultraviolet spectrophotometer (Beckman Coulter, Miami, FL, USA).

Flow cytometric analysis. The cultured cells were collected and resuspended in PBS at a density of $1 \times 10^{6} / \mathrm{ml}$. Subsequently, antibody linked with fluorochrome (mouse anti-human monoclonal MIC A/B IgG) was added and incubated for $30 \mathrm{~min}$ at $4^{\circ} \mathrm{C}$ in the absence of visible light. Following washing three times with PBS, the cells were detected by fluorescence-activated cell sorting (FACS) using a FACSCalibur instrument (BD Biosciences, Franklin Lakes, NJ, USA).

MTT analysis. The cells were cultured in 96-well plates. MTT $(20 \mu 1$ of $5 \mathrm{mg} / \mathrm{ml})$ was added to each well and the cells were incubated for $4 \mathrm{~h}$ at $37^{\circ} \mathrm{C}$. Following incubation, $100 \mu \mathrm{l}$ 
Table II. Expression levels of HIF-1 $\alpha$ and MICA/B according to clinicopathological parameters.

\begin{tabular}{|c|c|c|c|c|c|c|c|c|c|}
\hline \multirow[b]{2}{*}{ Parameter } & \multirow[b]{2}{*}{ Cases (n) } & \multicolumn{4}{|c|}{ HIF- $1 \alpha$} & \multicolumn{4}{|c|}{ MICA/B } \\
\hline & & Positives (n) & Positive rate $(\%)$ & $\chi^{2}$ & P-value & Low & High & $\chi^{2}$ & P-value \\
\hline \multicolumn{10}{|l|}{ Age } \\
\hline$<50$ & 18 & 14 & 77.8 & \multirow{2}{*}{0.025} & \multirow{2}{*}{$>0.05$} & 7 & 11 & \multirow{2}{*}{0.019} & \multirow{2}{*}{$>0.05$} \\
\hline$\geq 50$ & 24 & 18 & 75.0 & & & 10 & 14 & & \\
\hline \multicolumn{10}{|l|}{ Gender } \\
\hline Male & 32 & 24 & 75.0 & \multirow{2}{*}{0.010} & \multirow{2}{*}{$>0.05$} & 13 & 19 & \multirow{2}{*}{0.111} & \multirow{2}{*}{$>0.05$} \\
\hline Female & 10 & 8 & 80.0 & & & 4 & 6 & & \\
\hline \multicolumn{10}{|c|}{ TNM staging } \\
\hline I-II & 28 & 16 & 57.1 & \multirow{2}{*}{4.025} & \multirow{2}{*}{$<0.05$} & 6 & 22 & \multirow{2}{*}{10.389} & \multirow{2}{*}{$<0.05$} \\
\hline III-IV & 14 & 13 & 92.9 & & & 11 & 3 & & \\
\hline \multicolumn{10}{|c|}{ Differentiation } \\
\hline High & 12 & 9 & 75.0 & \multirow{3}{*}{1.116} & \multirow{3}{*}{$>0.05$} & 2 & 10 & \multirow{3}{*}{9.141} & \multirow{3}{*}{$<0.05$} \\
\hline Medium & 12 & 8 & 66.7 & & & 3 & 9 & & \\
\hline Low & 18 & 15 & 88.3 & & & 12 & 6 & & \\
\hline \multicolumn{10}{|c|}{ Pathological type } \\
\hline Tubular & 32 & 25 & 78.1 & \multirow{2}{*}{0.010} & \multirow{2}{*}{$>0.05$} & 12 & 20 & \multirow{2}{*}{0.111} & \multirow{2}{*}{$>0.05$} \\
\hline Papillary & 10 & 7 & 70.0 & & & 5 & 5 & & \\
\hline \multicolumn{10}{|c|}{ Lymphatic metastasis } \\
\hline Positive & 23 & 21 & 91.3 & \multirow{2}{*}{4.693} & \multirow{2}{*}{$<0.05$} & 9 & 14 & \multirow{2}{*}{0.014} & \multirow{2}{*}{$>0.05$} \\
\hline Negative & 19 & 11 & 57.9 & & & 8 & 11 & & \\
\hline
\end{tabular}

HIF-1 $\alpha$, hypoxia-inducible factor $1 \alpha$; MICA/B, major histocompatibility complex class I chain-related A/B; TNM, tumor-node-metastasis

Table III. Correlations between HIF-1 $\alpha$ and MICA/B.

\begin{tabular}{|c|c|c|c|c|}
\hline \multirow[b]{2}{*}{ HIF- $1 \alpha$} & \multicolumn{2}{|c|}{$\mathrm{MICA} / \mathrm{B}$} & \multirow[b]{2}{*}{$\mathrm{r}$} & \multirow[b]{2}{*}{ P-value } \\
\hline & Low $(0 / 1)$ & High (2) & & \\
\hline Low $(-/+)$ & 0 & 12 & \multirow{3}{*}{-0.522} & \multirow{3}{*}{$<0.001$} \\
\hline $\operatorname{High}(++/+++)$ & 17 & 13 & & \\
\hline Total & 17 & 25 & & \\
\hline
\end{tabular}

HIF-1 $\alpha$, hypoxia-inducible factor $1 \alpha$; MICA/B, major histocompatibility complex class I chain-related A/B.

$\longrightarrow$

MTT solution was added and the cells were agitated on an orbital shaker for $1 \mathrm{~min}$. The absorbance was then read at $570 \mathrm{~nm}$ using an Elx-800 microplate reader (Winooski, VT, USA).

Statistical analysis. All statistical analyses were performed using the SPSS 13.0 statistical software package (SPSS, Inc., Chicago, IL, USA). Differences between groups were compared using single factor analysis of variance and Student's t-test. $\mathrm{P}<0.05$ was considered to indicate a statistically significant difference between values.
Table IV. Expression of sMICA/B under different culturing conditions.

\begin{tabular}{lccc}
\hline $\begin{array}{l}\text { Conditions/ } \\
\text { supplements }\end{array}$ & Absorbance & $\begin{array}{l}\text { sMICA } \\
(\mathrm{pg} / \mathrm{ml})\end{array}$ & $\begin{array}{l}\text { sMICB } \\
(\mathrm{pg} / \mathrm{ml})\end{array}$ \\
\hline $20 \% \mathrm{O}_{2}$ & 0.598 & 127.14 & 3.664 \\
& 0.776 & 169.92 & 5.219 \\
& 0.654 & 140.60 & 3.495 \\
$20 \% \mathrm{O}_{2}+\mathrm{L}-\mathrm{NMMA}$ & 1.113 & 250.91 & 9.274 \\
& 1.429 & 326.86 & 7.077 \\
$0.5 \% \mathrm{O}_{2}$ & 1.127 & 254.28 & 6.165 \\
& 1.556 & 357.38 & 5.590 \\
$0.5 \% \mathrm{O}_{2}+\mathrm{GTN}$ & 1.388 & 317.00 & 7.517 \\
& 1.360 & 310.27 & 8.125 \\
& 0.868 & 192.03 & 6.030 \\
& 0.796 & 174.73 & 7.348 \\
\hline
\end{tabular}

Cells were cultured in Dulbecco's modified Eagle's medium containing $20 \%$ fetal bovine serum. HIF- $1 \alpha$, hypoxia-inducible factor $1 \alpha$; sMICA/B, soluble major histocompatibility complex class I chain-related $\mathrm{A} / \mathrm{B}$; GTN, glyceryl trinitrate; L-NMMA, NG-mono-methyl-L-arginine. 

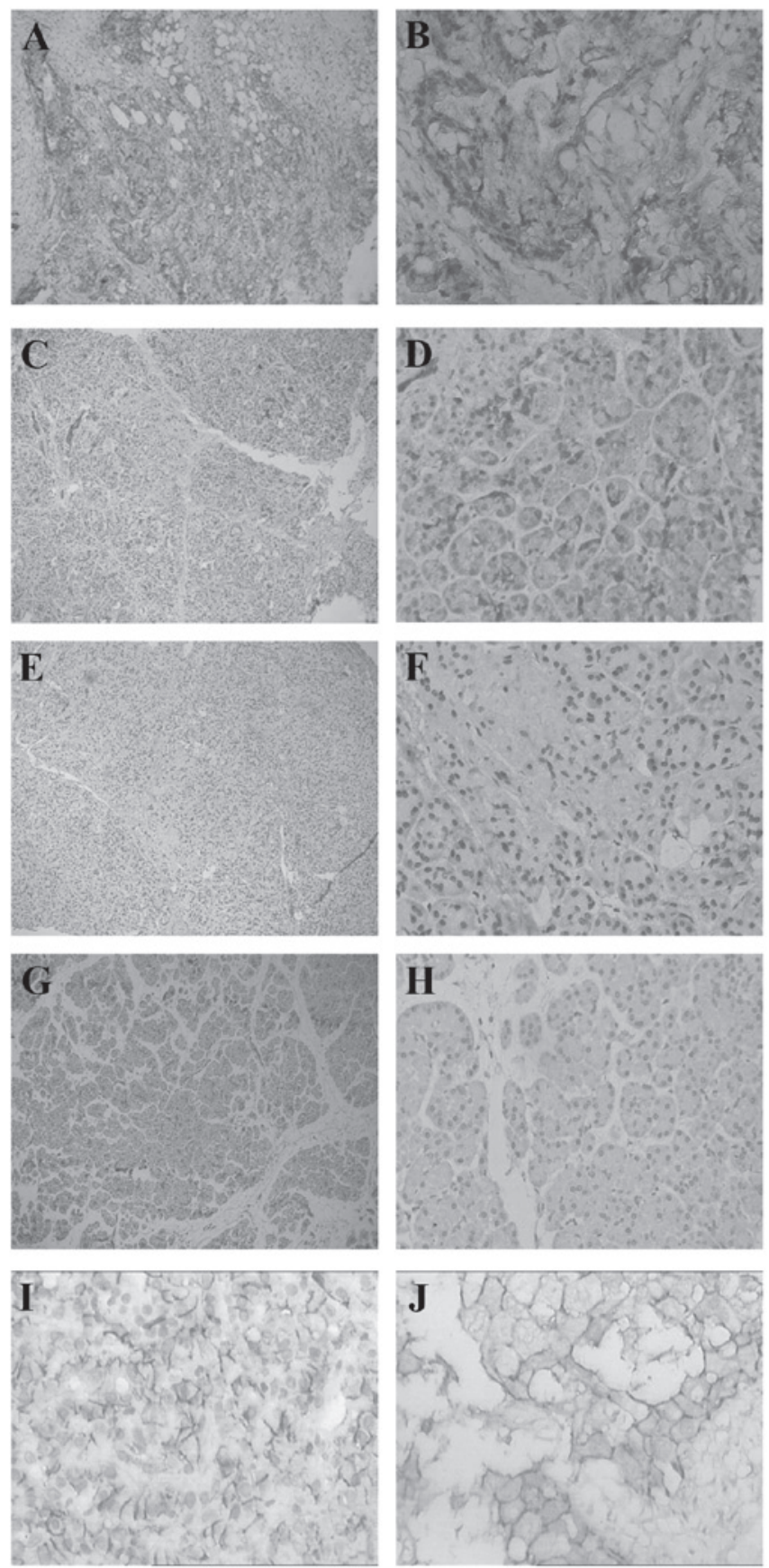

Figure 1. Expression levels of HIF-1 $\alpha$ and MIC in pancreatic carcinoma, chronic pancreatitis and normal pancreatic tissues. HIF-1 $\alpha$ in (A and $\mathrm{B}$ ) pancreatic carcinoma tissue, $(\mathrm{C}$ and $\mathrm{D})$ chronic pancreatitis tissue, ( $\mathrm{E}$ and $\mathrm{F})$ chronic pancreatitis tissue, and $(\mathrm{G}$ and $\mathrm{H})$ normal pancreas tissue. (I and J) MIC in pancreatic carcinoma tissue. Magnification: A, C E G and $\mathrm{H}, \mathrm{x} 100 ; \mathrm{B}, \mathrm{D}, \mathrm{F}, \mathrm{H}$ and $\mathrm{J}, \mathrm{x} 400$. Dark granules indicate positive staining. HIF-1 $\alpha$, hypoxia-inducible factor $1 \alpha$; MIC, major histocompatibility complex class I chain-related.

\section{Results}

Expression levels of HIF-1 $\alpha$ and MICA/B in pancreatic carcinoma, chronic pancreatitis and normal pancreatic tissues. As shown in Table I, protein expression of HIF-1 $\alpha$ was observed in 32 out of 42 pancreatic carcinoma samples and 2 out of 9 chronic pancreatitis samples; however, HIF-1 $\alpha$ protein was not detected in the normal pancreatic samples. In addition, protein expression of MICA/B was observed in 38 out of 42 pancreatic
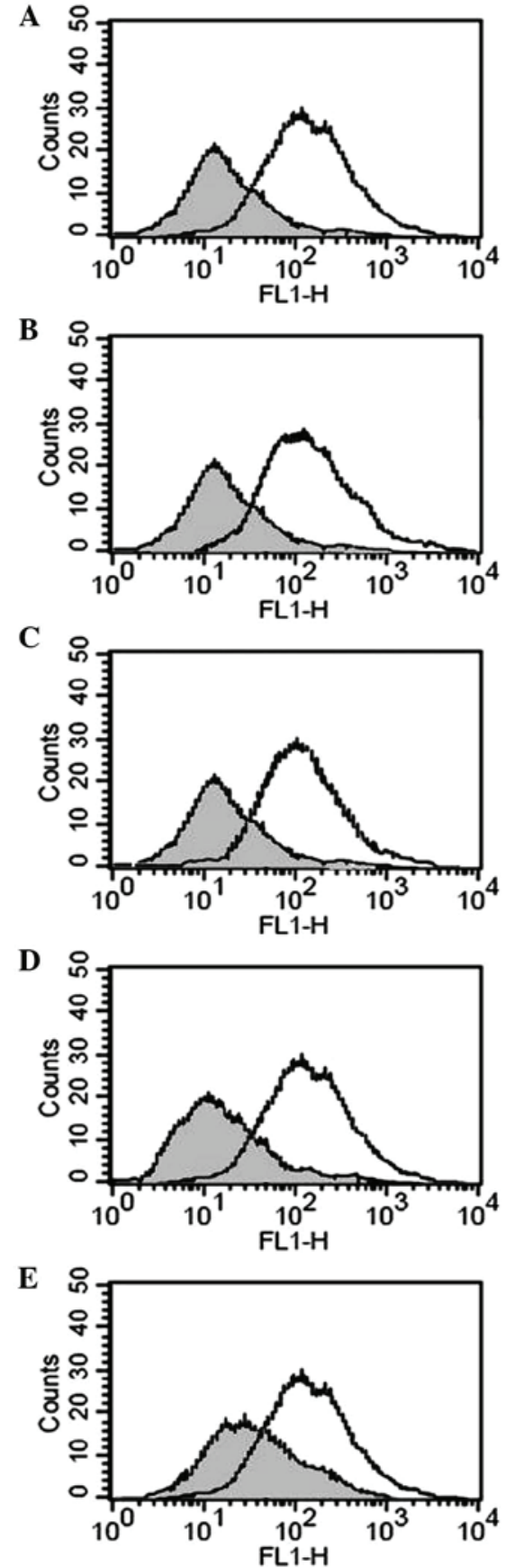

Figure 2. Protein expression of MIC in PANC-A cells under different culture conditions. (A) Cells cultured in $0.5 \% \mathrm{O}_{2}$ (grey) and $20 \% \mathrm{O}_{2}$. (B) Cells cultured in $0.5 \% \mathrm{O}_{2}$ (grey) and $0.5 \% \mathrm{O}_{2}+$ glyceryl trinitrate. (C) Cells cultured in $0.5 \%$ $\mathrm{O}_{2}$ (grey) and $0.5 \% \mathrm{O}_{2}+8$-bromoguanosine cyclic monophosphate. (D) Cells cultured in $20 \% \mathrm{O}_{2}$ and $20 \% \mathrm{O}_{2}+$ NG-mono-methyl-L-arginine, a nitric oxide synthase inhibitor (grey). (E) Cells cultured in 20\% $\mathrm{O}_{2}$ and 20\% $\mathrm{O}_{2}+\mathrm{KT} 5823$, a protein kinase G inhibitor (grey). HIF-1 $\alpha$, hypoxia-inducible factor $1 \alpha$; mMIC, membrane-bound major histocompatibility complex class I chain-related.

carcinoma samples and 2 out of 9 chronic pancreatitis samples, but was detected in only one normal pancreatic tissue sample. The expression levels of HIF-1 $\alpha$ and MICA/B were either positively or negatively correlated to tumor-node-metastasis (TNM) staging; however, no correlation with the pathological type was observed ( $\mathrm{P}>0.05$; Table II). According to Spearman's rank correlation coefficient, the two proteins were negatively correlated $(\mathrm{P}<0.001$; Table III). Immunohistochemistry also 
Table V. Cytotoxic activity of NK cells on PANC-1 cells.

\begin{tabular}{lcccc}
\hline & \multicolumn{4}{c}{$\begin{array}{c}\text { Cytotoxic activity of NK cells (\%) } \\
\text { (NK:PANC-1 cell ratio) }\end{array}$} \\
\cline { 2 - 5 } $\begin{array}{l}\text { Pre-incubation } \\
\text { conditions }\end{array}$ & $6.25: 1$ & $12.5: 1$ & $25: 1$ & $50: 1$ \\
\hline $20 \% \mathrm{O}_{2}$ & $32.4 \pm 5.1$ & $35.7 \pm 4.5$ & $40.7 \pm 5.9$ & $43.9 \pm 5.5$ \\
$20 \% \mathrm{O}_{2}+\mathrm{L}-\mathrm{NMMA}$ & $19.1 \pm 3.4$ & $22.1 \pm 4.2$ & $25.4 \pm 4.4$ & $33.3 \pm 5.1$ \\
$0.5 \% \mathrm{O}_{2}$ & $15.8 \pm 3.3$ & $17.7 \pm 2.9$ & $25.2 \pm 4.0$ & $29.1 \pm 4.2$ \\
$0.5 \% \mathrm{O}_{2}+$ GTN & $16.6 \pm 2.8$ & $21.8 \pm 3.1$ & $29.5 \pm 4.1$ & $38.2 \pm 5.7$ \\
\hline
\end{tabular}

Values are presented as the mean \pm standard deviation.NK,natural killer; GTN, glyceryl trinitrate; L-NMMA, NG-mono-methyl-L-arginine.

A

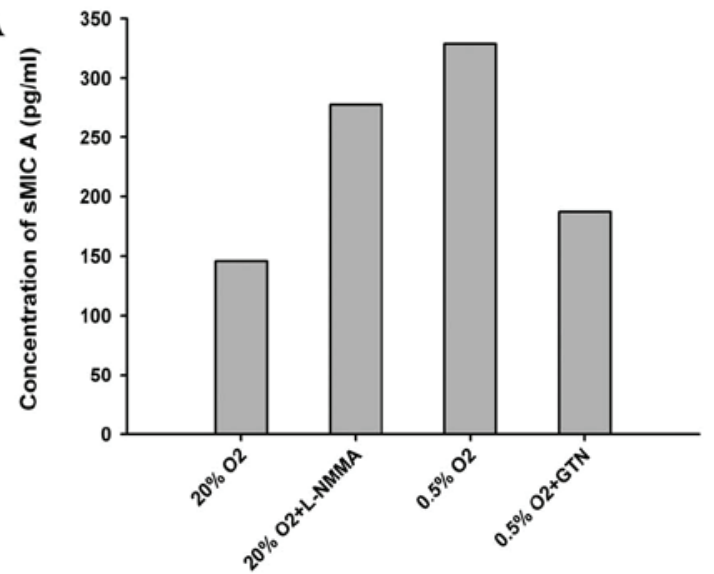

B

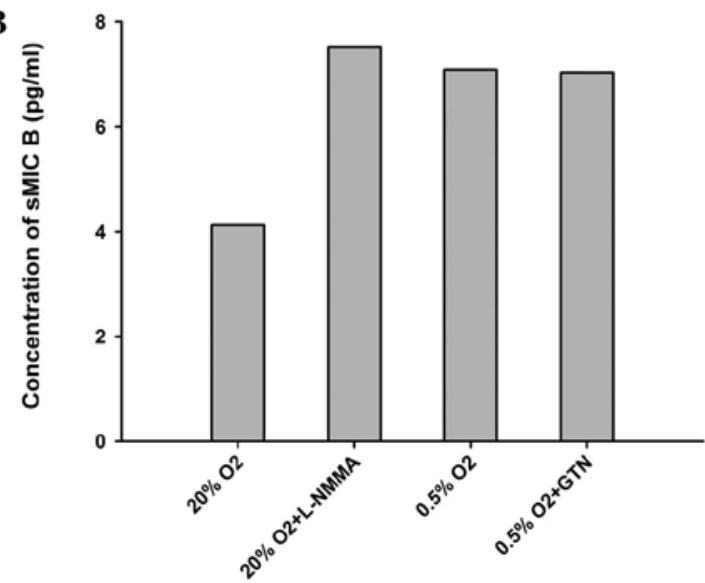

Figure 3. Expression of sMICA/B in medium under different culture conditions. (A) sMICA and (B) sMICB under different culture conditions. sMIC; soluble major histocompatibility complex class I chain-related; GTN, glyceryl trinitrate; L-NMMA, NG-mono-methyl-L-arginine.

revealed that, in the pancreatic carcinoma cells, the expression of MIC on the membrane was reduced; however, it was detected in the interstitial tissue (Fig. 1).

Effects of hypoxia on membrane-bound $(m)$ and soluble $(s)$ $M I C A / B$. As demonstrated previously, HIF-1 $\alpha$, regulated by hypoxia, was increased in pancreatic carcinoma tissues, while mMIC was decreased with accumulation in interstitial
A

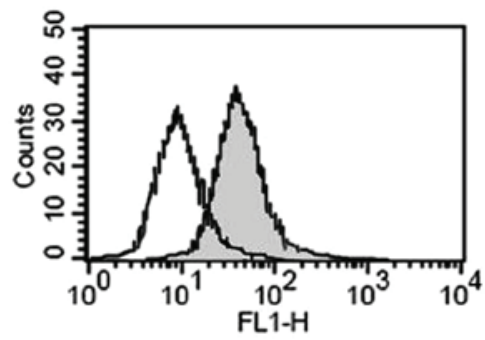

B

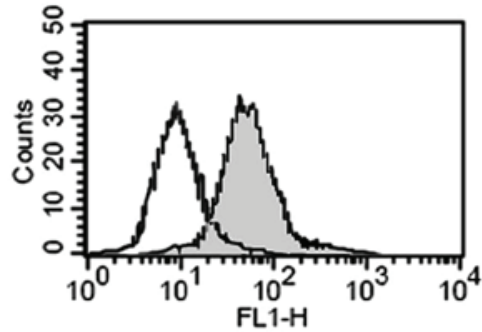

C

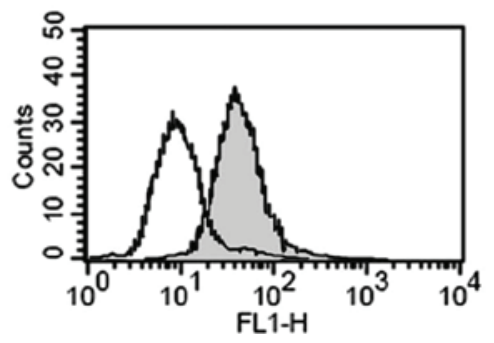

Figure 4. Expression of NK group 2, member D in NK cells co-incubated with PANC-1 cells at a ratio of $1: 1$ for $24 \mathrm{~h}$. (A) PANC-1 cells pre-incubated in $0.5 \% \mathrm{O}_{2}$ and $20 \% \mathrm{O}_{2}$ (grey). (B) PANC-1 cells pre-incubated under $0.5 \% \mathrm{O}_{2}$ and $0.5 \% \mathrm{O}_{2}+$ glyceryl trinitrate (grey). (C) PANC-1 cells pre-incubated under $20 \% \mathrm{O}_{2}$ (grey) and $20 \% \mathrm{O}_{2}+\mathrm{NG}$-mono-methyl-L-arginine; NK, natural killer.

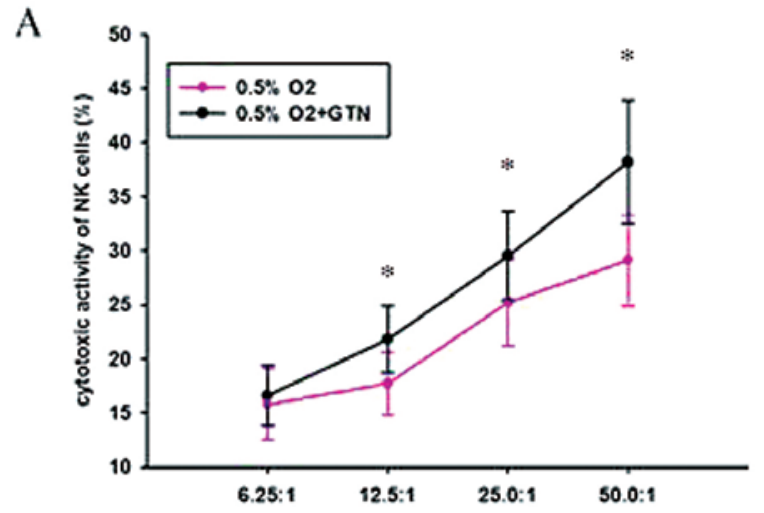

B

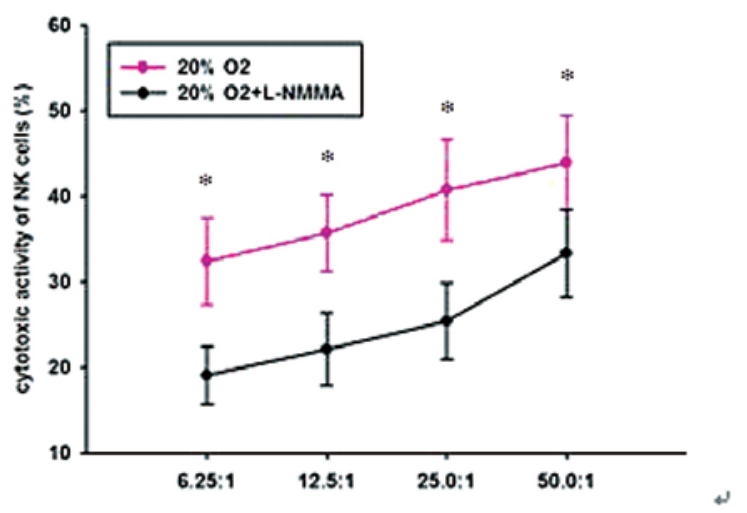

Figure 5. Cytotoxic activity of NK cells. (A) PANC-1 cells pre-cultured in $0.5 \%$ $\mathrm{O}_{2}$ and $0.5 \% \mathrm{O}_{2}+$ GTN. (B) PANC-1 cells pre-cultured in $20 \% \mathrm{O}_{2}$ and $20 \%$ $\mathrm{O}_{2}+\mathrm{L}-\mathrm{NMMA}$. ${ }^{*} \mathrm{P}<0.05$ vs. the other group at the same proportion. NK, natural killer; GTN, glyceryl trinitrate; L-NMMA, NG-mono-methyl-L-arginine. 
tissue (16). To assess whether hypoxia reduced mMIC and increased sMIC, the PANC-1 pancreatic carcinoma cell line was cultured in $0.5 \% \mathrm{O}_{2}$. The results revealed that the protein expression of mMIC decreased compared with that in cells cultured in $20 \% \mathrm{O}_{2}$ (Fig. 2). However, no clear differences were detected in the mRNA expression levels of mMICA/B between the two groups of cells. Furthermore, the addition of a single dose of either GTN (10 nM) or 8-Br-cGMP (10 nM) to the cells incubated for $24 \mathrm{~h}$ in $0.5 \% \mathrm{O}_{2}$ was sufficient to prevent the reduction in mMIC. Inhibiting nitric oxide (NO) synthesis with the NO synthase inhibitor L-NMMA $(5 \mu \mathrm{g} / \mathrm{ml})$ or suppressing protein kinase $\mathrm{G}$ (PKG) activity with the PKG inhibitor KT5823 $(10 \mu \mathrm{M})$ reduced the expression of mMIC in the cells cultured in $20 \% \mathrm{O}_{2}$ (Fig. 2). By contrast, sMICA increased $\sim 2$-fold $(\mathrm{P}<0.05)$ in $0.5 \% \mathrm{O}_{2}$, which was prevented by co-incubation with GTN (10 nM; Fig. 3). Co-incubation with L-NMMA $(5 \mu \mathrm{g} / \mathrm{ml})$ also increased the levels of sMICA (Table IV, Fig. 3). No significant differences were observed in sMICB (Table IV; Fig. 3).

Effect of hypoxia on the protein expression of NKG2D. To assess the effect of hypoxia on the protein expression of NKG2D, PANC-1 cells which were pre-incubated in $0.5 \%$ $\mathrm{O}_{2}$ and $20 \% \mathrm{O}_{2}$ with or without GTN and L-NMMA were collected and co-incubated with NK cells. As Fig. 4 shows, compared with the cells incubated in $20 \% \mathrm{O}_{2}$, those cultured in $0.5 \% \mathrm{O}_{2}$ had lower protein expression levels of NKG2D (40.5 vs. $70.3 \%$ ). The addition of GTN promoted the expression of NKG2D to $62.5 \%$, while L-NMMA downregulated the expression to $48.4 \%$ (Fig. 4).

Effect of hypoxia on the cytotoxic activity of NK cells. To determine the effect of hypoxia on the cytotoxic activity of NK cells, the PANC-1 cells were pre-cultured under different conditions and then co-incubated with NK cells in varying proportions (1:6.25, 1:12.5, 1:25 and 1:50) for $24 \mathrm{~h}$. An MTT assay revealed that cells cultured in $0.5 \% \mathrm{O}_{2}$ were more tolerant to the NK cells compared with those incubated in $20 \% \mathrm{O}_{2}$. GTN increased the cytotoxic activity and L-NMMA decreased the cytotoxic activity of the NK cells (Table V; Fig. 5).

\section{Discussion}

The present study demonstrated an increase in the levels of sMIC, resulting in a decrease in the protein expression of NKG2D, which was key in regulating the hypoxia-mediated immune evasion of human pancreatic carcinoma cells. Furthermore, the results of the present study clearly suggested that NO signaling was essential in this process.

Pathological slides revealed that HIF-1 $\alpha$ was highly expressed in pancreatic carcinoma tissues, which indicated that hypoxia was present in the pancreatic carcinoma. In addition, MIC decreased compared with the chronic pancreatitis and normal pancreatic tissues, suggesting that hypoxia may downregulate MIC.

To mimic the hypoxic microenvironment experienced by cancer cells, the present study cultured the PANC-1 cell line in $0.5 \% \mathrm{O}_{2}$, with control cells cultured in $20 \% \mathrm{O}_{2}$. The results demonstrated that the expression of HIF-1 $\alpha$ was high and that of MIC was low (data not shown). However, RT-qPCR revealed no clear differences in the mRNA expression of MICA/B between cells cultured in $0.5 \% \mathrm{O}_{2}$ and $20 \% \mathrm{O}_{2}$, raising the question of whether this was due to downregulation of MIC translation or detachment of MIC to the extracellular space. ELISA demonstrated that the level sMIC, particularly sMICA, increased in the cell culture medium exposed to $0.5 \%$ $\mathrm{O}_{2}$, which had a negative effect on the expression of NKG2D and the cytotoxic activity of NK cells. The results indicated that hypoxia did not inhibit the gene expression of MIC, but induced the detachment of MIC from the cell membrane and downregulated the expression of NKG2D and the cytotoxicity of NK cells. This resulted in the reduced immunogenicity of cancer cells and subsequent evasion of the immune system. Matrix metalloproteinases (MMP) may be important molecules in this regulation, as it has been reported that MMP-2 and -9 are often upregulated in tumors (17). Salih et al (18) investigated the addition of MMP inhibitor to the medium, which revealed marked increases in mMIC. Another study confirmed that the hypoxia-induced detachment of mMIC is regulated by MMPs (19). However, the reason for downregulation in the expression of NKG2D and NK cytotoxicy remain to be elucidated. One theory is that the binding of sMIC and NKG2D causes the internalization of NKG2D. Doubrovina et al (20) demonstrated that following binding to soluble MIC, NKG2D is decreasingly located at the membrane and is increasingly present in the cytoplasm. Groh et al (21) also observed that sMIC induced the internalization and degradation of NKG2D on $\mathrm{T}$ cells.

Studies have also demonstrated that hypoxia markedly inhibits the cellular NO-cGMP-PKG pathway (22-25). Inhibiting the pathway with drugs has a mimetic effect of hypoxia (26-29). In the present study, GTN and 8-Be-cGMP were used as NO-cGMP-PKG pathway stimulators, and L-NMMA and KT5823 were used as inhibitors. Treatment with GTN and 8-Be-cGMP reduced sMICA and promoted the expression of NKG2D and NK cytotoxicity, whereas treatment with L-NMMA and KT5823 had an opposite effect. It is understood that the NO-cGMP-PKG pathway begins with NO synthesis. As a soluble gas molecule, NO passes through the cell membrane and activates soluble guanylyl cyclase (sGC), which catalyzes the conversion of GTP to cGMP. cGMP then acts as a secondary messenger, activating PKG and amplifying NO signals to downstream effectors (26). According to the results of the present study, activation of the NO-cGMP-PKG pathway weakened the hypoxia-mediated immune evasion of pancreatic carcinoma cells.

All the experiments in the present study were performed in vitro and, as there is greater interest in the immune response in vivo, subsequent investigation aims to establish a nude mouse model to study the effect of NO-mimetic drugs on tumorigenicity.

In conclusion, the results of the present study indicated that the NO-cGMP-PKG signaling pathway regulated the immune escape observed in pancreatic cancer. Activation of this pathway can reverse the immune escape, whereas its inhibition promoted the immune escape. The hypoxic environment, which the pancreatic cancer cells existed in, was closely associated with this signaling pathway. Further research on NO-cGMP-PKG signal pathway and hypoxia environment 
will provide novel directions for the development of immunotherapies for pancreatic cancer.

\section{References}

1. Zhang J, Xie X and Ye D: Adhesion molecules and tumor immune escape. Shi Yong Zhong Liu Xue Zha Zhi 19: 449-452, 2004 (In Chinese).

2. Ogiso Y, Tomida A, Lei S, et al: Proteasome inhibition circumvents solid tumor resistance to topoisomerase II-directed drugs. Cancer Res 60: 2429-2434, 2000.

3. Fink T, Ebbesen P, Koppelhus U and Zachar V: Natural Killer cell-mediated basal and interferon-enhanced cytotoxicity agains liver cancer cells is significantly impaired under in vivo oxygen conditions. Scand J Immunol 58: 607-612, 2003.

4. Ivan M: HIF-1 $\alpha$ targeted for VHL-mediated destruction by praline hydroxylation: implications for $\mathrm{O}_{2}$ sensing. Science 292 464-468, 2001.

5. Semenza G: Signal transduction to hypoxia-inducible factor 1. Biochem Pharmacol 64: 993-998, 2002.

6. Ivan M: HIF-1 $\alpha$ targeted for VHL-mediated destruction by praline hydroxylation: implications for $\mathrm{O}_{2}$ sensing. Science 292: 464-468, 2001.

7. Groh V, Rhinehart R, Secrist H, et al: Broad tumor-associated expression and recognition by tumor-derived gamma delta T cells of MICA and MICB. Proc Natl Acad Sci USA 96: 6879-6884, 1999.

8. Li K, Mandai M, Hamanishi J, et al: Clinical significance of the NKG2D ligands, MICA/B and ULBP2 in ovarian cancer: high expression of ULBP2 is an indicator of poor prognosis. Cancer Immunol Immunother 58: 641-652, 2009.

9. Diefenbach A, Jensen ER, Jamieson AM and Raulet DH: Rael and H60 ligands of the NKG2D receptor stimulate tumour immunity. Nature 413: 165-171, 2001.

10. Groh V, Steinle A, Bauer S and Spies T: Recognition of stress-induced MHC molecules by intestinal epithelial gammadelta T cel1s. Science 279: 1737-1740, 1998.

11. Conejo-Garcia JR, Benencia F, Courreges MC, et al: A tumor-associated NKG2D immunoreceptor ligand, induces activation and expansion of effector immune cells. Cancer Biol Ther 2: 446-451, 2003.

12. Vivier E, Tomasello E and Paul P: Lymphocyte activation via NKG2D: towards a new paradigm in immune recognition. Curr Opin Immunot 14: 306-311, 2002.

13. Holdenrieder S, Stieber P, Peterfi A, et al: Soluble MICA in malignant diseases. Int Cancer 118: 684-687, 2006.

14. Li K, Mandai M, Hamanishi J, Matsumura N, et al: Clinical significance of the NKG2D ligands, MICA/B and ULBP2 in ovarian cancer: high expression of ULBP2 is an indicator of poor prognosis. Cancer Immunol Immunother 58: 641-652, 2009.
15. Zhong H, De Marzo AM, Laughner E, et al: Overexpression of hypoxia-inducible factor lalpha in common human cancers and their metastases. Cancer Res 59: 5830-5835, 1999.

16. Duan X, Deng L, Chen X, et al: Clinical significance of the immunostimulatory MHC class I chain-related molecule A and NKG2D receptor on NK cells in pancreatic cancer. Med Oncol 28: 466-467, 2011.

17. Peng TS, Wu JS, Wu HQ, et al: The expression of matrix metalloproteinase-2,9 and their inhibitors in osteosarcoma. Journal of Sun Yatsen University (Medical Sciences) 2: 132-135, 2003 (In Chinese)

18. Salih HR, Rammensee HG and Steinle A: Down-regulation of MICA on human tumors by proteolytic shedding. J Immunol 169: 4098-4102, 2002.

19. Siemens DR, Hu N, Sheikhi AK, et al: Hypoxia increases tumor cell shedding of MHC class I chain-related molecule: role of nitric oxide. Cancer Res 68: 4746-4753, 2008.

20. Doubrovina ES, Doubrovin MM, Vider E, et al: Evasion from NK cell immunity by MHC class I chain-related molecules expressing colon adenocarcinoma. J Immunol 171: 6891-6899, 2003.

21. Groh V, Wu J, Yee C and Spies T: Tumour-derived soluble MIC ligands impair expression of NKG2D and T-cell activation. Nature 419: 679-680, 2002

22. Whorton AR, Simonds DB and Piantadosi CA: Regulation of nitric oxide synthesis by oxygen in vascular endothelial cells. Am J Physiol 272: L1161-L1166, 1997.

23. McCormick CC, Li WP and Calero M: Oxygen tension limits nitric oxide synthesis by activated macrophages. Biochem J 350: 709-716, 2000

24. Nathan $\mathrm{C}$ and Xie QW: Regulation of biosynthesis of nitric oxide. J Biol Chem 269: 13725-13728, 1994.

25. Louis CA, Reichner JS, Henry WL Jr, et al: Distinct arginase isoforms expressed in primary and transformed macrophages: regulation by oxygen tension. Am J Physiol 274: R775-R782, 1998

26. Frederiksen LJ, Sullivan R,Maxwell LR, et al: Chemosensitization of cancer in vitro and in vivo by nitric oxide signaling. Clin Cancer Res 13: 2199-2206, 2007.

27. Postovit LM, Adams MA, Lash GE, Heaton JP and Graham CH: Oxygen-mediated regulation of tumour cell invasiveness: involvement of a nitric oxide signalling pathway. Biol Chem 277: 35730-35737, 2002.

28. Postovit LM, Adams MA, Lash GE, Heaton JP and Graham CH: Nitric oxide-mediated regulation of hypoxia-induced B16F10 melanoma metastasis. Int J Cancer 108: 47-53, 2004.

29. Matthews NE, Adams MA, Maxwell LR, Gofton TE and Graham CH: Nitric oxide-mediated regulation of chemosensitivity in cancer cells. Natl Cancer Inst 93: 1879-1885, 2001. 